\title{
Socio-demographic Characteristics and Food Hygiene Level Assessment of Food Handlers in Cafeterias around a Federal University in Nigeria
}

\author{
C. E. Aruwa ${ }^{1 *}$, A. J. Akindusoye ${ }^{1}$ and S. I. Awala ${ }^{1}$ \\ ${ }^{1}$ Department of Microbiology, Federal University of Technology, P.M.B. 704, Akure, Nigeria.
}

Authors' contributions

This work was carried out in collaboration between all authors. Author CEA designed and supervised the study, reviewed statistical analyses and study protocol, wrote and submitted the first draft of the manuscript. Author AJA managed the analyses of the study. Author SIA managed the literature proof read. All authors read and approved the final manuscript.

Article Information

DOI: $10.9734 / J S R R / 2017 / 33273$

Editor(s):

(1) Surapong Pinitglang, Department of Food Science and Technology, School of Science and Technology, University of the Thai Chamber of Commerce, Thailand.

Reviewers:

(1) Ngwa Niba Rawlings, National Polytechnic, Bambui, Bamenda, Cameroon.

(2) Anthony C. Iwu, Imo State University Teaching Hospital Orlu, Nigeria.

(3) Akindele, Peter Oluwayinka, Federal University of Technology, Akure, Nigeria.

(4) Isabelle Luz, Oswaldo Cruz Institute, Fiocruz, Rio de Janeiro-RJ, Brazil.

(5) Paula Tavolaro, Centro Universitário das Faculdades Metropolitanas Unidas, Brazil.

Complete Peer review History: http://www.sciencedomain.org/review-history/19363

Original Research Article

Received $7^{\text {th }}$ April 2017

Accepted $28^{\text {th }}$ May 2017

Published $6^{\text {th }}$ June 2017

\section{ABSTRACT}

Background and Objective: Globally, food hygiene/food borne illnesses remain subjects of great concern. This study sought to assess the knowledge, attitude and practice of food hygiene; and to determine the types, prevalence and load of microbial isolates among food handlers' in cafeterias around a University in South-Western Nigeria. It also highlighted the socio-demographic characteristics of food handlers/respondents.

Study Design: A cross sectional descriptive design was used, followed by sample collection and analyses.

Place and Duration of Study: Study was carried out over a period of three months at cafeterias around the University campus gates.

Methodology: A cross sectional descriptive design using a simple random sampling technique to select 50 participants from six major cafeterias around the University. Data was collected using a structured questionnaire. Microbial samples collected using palm imprint method, prior to microbial 
isolation and identification. Descriptive analyses were done with frequency and summary statistics, and SPSS version 15 to determine significant relationships with the $\mathrm{p}$ set at 0.05 significance level.

Results: Majority of respondents were female $(70 \%)$. A higher percentage $(46 \%)$ of respondents was between $20-29$ years. More than half $(62 \%)$ of respondents were married. Knowledge of food hygiene was good (42\%), likewise the attitude (34\%), but only one fifth of respondents had good food hygiene practices. Escherichia coli had the highest occurrence (18.9\%) of all bacteria. Aspergillus niger had the highest occurrence (31.6\%) of all fungal isolates. Hygiene level of respondents was generally low due to the high occurrence of $E$. coli.

Conclusion: Knowledge of food hygiene amongst food handlers was not complemented by good hygiene practices. Research findings serve as an early warning system to aid implementation of monitoring systems, and spur urgent action from relevant authorities.

Keywords: Food hygiene; practice; socio-demographic characteristics; vendors; Nigeria.

\section{INTRODUCTION}

Food hygiene practices are a subject of broad scope. It describes the preservation and preparation of foods in a manner that ensures that food is safe for human consumption [1]. Food hygiene deals with the prevention of contamination of food stuffs at all stages of production, collection, transportation, storage, preparation, sale and consumption [2]. This process of kitchen safety includes proper storage of food items prior to use, maintaining a clean environment when preparing the food, and making sure that all served dishes are free of germ that could lead to some type of contamination. The food storage aspect of food hygiene is focused on maintaining the quality of the food, so that it will be fresh when used in different recipes. Food safety is a scientific discipline describing handling, preparation, and storage of food in ways that prevent food-borne illnesses. This includes the number of routines that should be followed to avoid potentially severe health hazards. Food can transmit diseases from one person to the other as well as serve as a growth medium for bacteria that can cause food poisoning. Food handlers themselves can also serve as contamination sources for the foods they prepare [3].

Infectious microorganisms or their toxins can contaminate food at any point of processing or production. The most common food borne pathogens are norovirus, Escherichia coli, Salmonella typhi, Clostridium perfringens, Campylobacter sp., and Staphylococcus aureus. Food poisoning symptoms which can start within hours of eating contaminated food often include abdominal pain, watery stools, fever, nausea, vomiting or diarrhoea [4]. More serious cases of food poisoning can result in life-threatening neurologic, hepatic, and renal syndromes leading to permanent disability or death [4,5]. Depending on the symptoms, cause, and severity of food poisoning, certain drugs may be prescribed more often on an in-patient basis. These drugs include oral rehydration salt (ORS), intravenous fluids, antibiotics, antitoxin for Clostridium botulinum poisoning, ipecac, atropine for mushroom poisoning etc. It is a widespread and growing public health problem both in developed and developing countries; the effect being more devastating in developing countries [6]. A food handler is a person with any job that requires handling unpackaged foods or beverages and involved in preparing, manufacturing, serving, inspecting, or even packaging food and beverage items. Hands of food outlet employees have been shown to be vectors in the spread of foodborne diseases, mainly because of poor personal hygiene [7]. Food handlers with poor personal hygiene working in food-serving establishments could be potential sources of infections of many intestinal helminths, protozoa, and enteropathogenic bacteria may contaminate foods from their faeces via their fingers, then to food, and finally to healthy individuals. Compared to other parts of the hand, the area beneath fingernails harbours the most microorganisms and is most difficult to clean. All food handlers are required to observe proper hygiene and sanitation methods when working with food [8], as the chances of food contamination largely depends on health status and hygiene practices. Hence, lack of adequate food hygiene can lead to food-borne diseases and death of the consumers [6]. Globally, food-borne illnesses affect an estimated $30 \%$ of individuals annually. Meals prepared outside the home have been implicated in up to $70 \%$ of trace outbreaks [9].

Okojie et al. [8] in an assessment of food hygiene practices involving 102 respondents/food handlers in a Nigerian University campus 
reported that the knowledge and practice of food hygiene and safety was poor. Only $30.4 \%$ of respondents had pre-employment medical examination and $48 \%$ had some form of health education on food hygiene and safety. In the study of Musa and Akande [10] involving $98 \%$ of female respondents; $56.8 \%$ had no formal education while $39 \%$ had received training on food hygiene. Pre-employment medical examination was practice in most cases, but post-employment periodic medical examination was greatly reduced. Only $33 \%$ of respondents prepared food well in advance, while $39 \%$ reheat food before sale. The major unhygienic practices observed among the food vendors were poor care of used utensils $(54 \%)$, use of previously used water for washing and cleaning, lack of covering apron among the vendors (69\%) and lack of wash hand basin for immediate cleaning (33\%). Forty-six percent of respondents used soap and water to clean their utensils. In 2009, Isara and colleague reported good safety practices among food handlers in fast food restaurants in Benin City, Nigeria. They showed that knowledge and practice were influenced by previous training, whereas food handlers who had worked for longer years had better knowledge and practiced food hygiene. The level of education did not significantly influence practice [11]. Oranusi et al. [12] reported the presence of Proteus spp., Staphylococcus aureus, Shigella spp., Bacillus cereus, Pseudomonas aeruginosa, Klebsiella spp., Salmonella spp., Neiseria spp., Escherichia coli, Penicilium spp., Aspergillus niger, Enterococci, Streptococcus spp., Candida spp., and Rhizopus spp. from forty (40) food handlers hand swabs and twenty (20) easy contact surfaces within the food outlets. One common way by which transient microorganisms of hands are picked up is by contact with food and surfaces especially surfaces the hand come in contact with mostly and frequently [12].

Consumers have a reasonable expectation that the foods they purchase have been produced and processed under hygienic condition and that the food has not been adulterated by addition of any biological, chemical, or physical hazard. Several agencies at local and international levels are burdened with this task, and are expected to enforce by regulations that govern production, processing, distribution and retailing of foods and drugs in any country [6]. It must be noted that proper handling, storage and preparation are essential to prevent food borne illnesses. However, in low and middle income nations the main issue is simply the availability of adequate safe water. This study therefore aimed at assessing the food hygiene practices of food handlers. This would aid in putting forward informed recommendations for improved food safety measures within food establishments around the University's community. Also, to isolate and characterize microorganisms associated with food handlers which may cause food poisoning, while examining the food handlers' knowledge of food hygienic practices in small or large subsistence food vending businesses. The study also discussed the current status of sanitation management performances in food outlets.

\section{MATERIALS AND METHODS}

\subsection{Study Area, Design and Participants}

The study involved fifty respondents from six major subsistence food vending outlets around major and mini campuses of a Federal University in South-Western (Akure, Ondo State) Nigeria. Akure is the capital city of Ondo State, with the major tribe being Yoruba. Central to the city's growing economy are agricultural (plant and livestock) production practices, as well as commerce (including small and medium scale businesses). The dominant religion is Christianity. However, Islamic groups are also present.

A cross sectional descriptive design and random sample of food vendors were used. The fivecategorical scale (very good, good, fair, poor and very poor) was utilized to classify respondent responses. Questions were designed to elicit sociodemographic characteristics, knowledge of personal and food hygiene, and food hygiene practices [13]. Informed consent was obtained from prospective respondents before questionnaire administration.

\subsection{Preparation of Questionnaire and Data Collection}

The questionnaire was prepared by constructing structured questions on various aspects of food hygiene. It was used to collect information from each food handler from different food outlet on knowledge, attitude and practice of food hygiene. The first part of the questionnaire was on sociodemographics while the later part covers questions on knowledge of food hygiene, attitude towards hygiene, practice of hygiene, pre- 
employment medical examination on suitability to handle food. The practice of food hygiene based on the level of education and duration of stay in the business was estimated with the corresponding responses. Data was collected using quantitative methods (structured interviewer-administered questionnaires) [14]. The food handlers were interviewed with the aid of the questionnaires and responses obtained were recorded accordingly. Attitude towards food hygiene was tested on management of left over foods, food protection from contamination, and their attitude towards sick people in the food business. Practice of food hygiene was computed based on how often work surfaces were kept clean, and if sanitization followed hand washing.

\subsubsection{Inclusion and exclusion criteria}

The key/principal individuals directly involved in the preparation of foods around the campus, and major cafeterias regularly visited by the institution's students and staff was selected. Only the subsistence level food vendors (food stalls or street vendors and the likes) qualified for the study.

\subsection{Microbial Sample Collection and Analysis}

Fifty (50) samples collected from palms (palm print method) of food handlers in six (6) major food outlets around Federal University of Technology, Akure using the palm imprint method [15]. Sterile, solidified poured plates of each culture media [Eosin methylene blue (EMB) agar, potato dextrose agar (PDA), plate count agar (PCA)] were prepared and taken to each food outlet. Slightly opening the plates, the food handlers placed the palm of each hand on the surface of individual plates containing PDA, PCA, and $E M B$ agar respectively for $15 \mathrm{~s}$. Plates were taken to the laboratory and all prints were left to dry for at least $30 \mathrm{~min}$ before incubating; PDA plates for fungi isolation at $25 \pm 2{ }^{\circ} \mathrm{C}$ for $48-72 \mathrm{hrs}$, EMB and PCA plates at $37^{\circ} \mathrm{C}$ for $24 \mathrm{hrs}$ for bacteria isolation.

\subsubsection{Enumeration and purification of $\underline{\text { microbial isolates }}$}

Microbial colonies were counted, and distinct colonies were sub-cultured from countable plates using the four-quadrant streak method to obtain pure bacterial cultures. The pure cultures of the bacteria isolated were each maintained in nutrient agar slants and refrigerated at $4^{\circ} \mathrm{C}$. Fungal isolates were purified by the transfer of fungal mycelia plug onto sterile freshly prepared PDA plates. Pure cultures of the fungi isolated were maintained on PDA slants in McCartney bottles and kept in the refrigerator at $4^{\circ} \mathrm{C}$ [16].

\subsubsection{Identification of microbial isolates}

This was carried out according to the method of Cheesbrough [17]. Here, hydrogen gas production and motility were observed and noted, while Gram's staining was carried out to ascertain the morphology and Gram's reaction of the isolates. Other biochemical tests carried out include catalase, coagulase, urease, spore staining and sugar fermentation. Fungal isolates were identified using microscopic and macroscopic mycelial morphologies.

\subsection{Statistical Analysis}

Descriptive analyses were done with frequency and summary statistics, and one-way ANOVA in SPSS version 15 for separation of means and to determine significant relationships with the $p$ set at 0.05 significance level.

\section{RESULTS}

\subsection{Socio-demographic Statistics of Food Handlers}

All respondents were of the Yoruba tribe with majority female $(70 \%)$, within the ages of $20-39$ years $(66 \%)$, married $(62 \%)$ and with either a secondary or higher level of education (72\%). Only $8 \%$ of food handlers had no formal education, and most belonged to the Yoruba tribe (Table 1).

\subsection{Food Hygiene Knowledge, Attitude and Practice of Food Handlers}

Forty-two and twenty-four percent of handlers had very good and good knowledge of food hygiene respectively (i.e. food storage, proper cooking, and importance of hand washing). Less than half $(26 \%$ and $34 \%)$ of the food handlers had very good and good attitude respectively towards food hygiene. Twenty-two percent had poor hygiene attitude. However, only $10 \%$ of respondents practiced good food hygiene (Table 2). 
Table 1. Socio-demographic characteristics of selected food handlers

\begin{tabular}{lll}
\hline Characteristics & $\begin{array}{l}\text { Frequency } \\
(\mathbf{n}=50)\end{array}$ & $\begin{array}{l}\text { Percentage } \\
(\%)\end{array}$ \\
\hline Sex & 15 & 30 \\
M & 35 & 70 \\
F & & \\
$\begin{array}{l}\text { Age category } \\
\text { (years) }\end{array}$ & & \\
$10-19$ & 5 & 10 \\
$20-29$ & 23 & 46 \\
$30-39$ & 10 & 20 \\
$40-49$ & 8 & 16 \\
$50-59$ & 4 & 8 \\
Marital status & & \\
Single & 19 & 38 \\
Married & 31 & 62 \\
Tribe & & \\
Hausa & 0 & 0 \\
Yoruba & 50 & 100 \\
lgbo & 0 & 0 \\
Educational & & \\
status & & \\
Primary & 10 & 20 \\
Secondary & 26 & 52 \\
Higher & 10 & 20 \\
None & 4 & 8 \\
\hline
\end{tabular}

Table 2. Food hygiene knowledge, attitude and practice among food handlers

\begin{tabular}{lll}
\hline $\begin{array}{l}\text { Level of } \\
\text { knowledge }\end{array}$ & $\begin{array}{l}\text { Frequency } \\
(\mathbf{n}=\mathbf{5 0})\end{array}$ & $\begin{array}{l}\text { Percentage } \\
(\%)\end{array}$ \\
\hline Very good & 12 & 24 \\
Good & 21 & 42 \\
Fair & 7 & 14 \\
Poor & 5 & 10 \\
Very poor & 5 & 10 \\
Total & $\mathbf{5 0}$ & $\mathbf{1 0 0}$ \\
Hygiene & & \\
attitude & & \\
Very good & 13 & 26 \\
Good & 17 & 34 \\
Fair & 9 & 18 \\
Poor & 11 & 22 \\
Very poor & 0 & 0 \\
Total & $\mathbf{5 0}$ & $\mathbf{1 0 0}$ \\
Hygiene & & \\
practice & & \\
Very good & 11 & 22 \\
Good & 5 & 10 \\
Fair & 8 & 16 \\
Poor & 11 & 22 \\
Very poor & 15 & 30 \\
Total & $\mathbf{5 0}$ & $\mathbf{1 0 0}$ \\
\hline
\end{tabular}

\subsection{Pre-employment Medical Examination History of Food Handlers}

Seventy percent of handlers had no preemployment medical examination (Table 3).

Table 3. Pre-employment medical examination history of food handlers

\begin{tabular}{lll}
\hline $\begin{array}{l}\text { Medical } \\
\text { examination }\end{array}$ & $\begin{array}{l}\text { Frequency } \\
(\mathbf{n}=\mathbf{5 0})\end{array}$ & $\begin{array}{l}\text { Percentage } \\
(\mathbf{\%})\end{array}$ \\
\hline Yes & 15 & 30 \\
No & 35 & 70 \\
Total & $\mathbf{5 0}$ & $\mathbf{1 0 0}$ \\
\hline
\end{tabular}

\subsection{Practice of Food Hygiene by Food Handlers Based on Level of Education}

Ten percent of primary school leavers showed good practice of food hygiene, while the highest group of handlers with poor food hygiene practice $(25 \%)$ had no formal education (Table 4).

\subsection{Practice of Food Hygiene by Handlers Based on Duration in Food Handling Business}

Table 5 showed a significant effect of duration of stay in food business on practice of food hygiene. Twenty-five of food handlers who had stayed in the business for 20-29 years practiced good hygiene, while those who had stayed in the business for shorter periods (0-9 years) had poor practice $(6.7 \%)$ of food hygiene.

\subsection{Average Microbial Load by Culture Media}

Table 6 showed an average bacterial count of $57 \mathrm{cfu}$ on EMB, 38cfu on NA, and 19sfu on PDA. E. coli had the highest prevalence $(18.9 \%)$ in all canteens (Table 6).

\subsection{Types and Prevalence of Microbial Isolates According to Sample Location}

Aspergillus niger was the most prevalent (31.6\%) fungal isolate from all canteens. Rhizopus sp. was the least $(5.3 \%)$ prevalent (Table 7$)$. Most prevalent bacteria were E. coli (18.9\%) and Staphylococcus aureus (17.9\%). Least prevalent of the bacterial isolates include Pseudomonas aeruginosa, Proteus vulgaris, Klebsiella pneumonia, with prevalence range between 3$4.2 \%$. 
Table 4. Practice of food hygiene by food handlers based on level of education

\begin{tabular}{lllllll}
\hline Educational level & \multicolumn{4}{c}{ Practice of food hygiene frequency (\%) } & \multirow{2}{*}{ Total (\%) } \\
\cline { 2 - 6 } & Good & Fair & Poor & Very good & Very poor & \\
\hline None & $0(0 \%)$ & $0(0 \%)$ & $1(25 \%)$ & $0(0 \%)$ & $3(75 \%)$ & $4(100)$ \\
Primary & $2(20 \%)$ & $2(20 \%)$ & $3(30 \%)$ & $1(10 \%)$ & $2(20 \%)$ & $10(100)$ \\
Secondary & $2(7.7 \%)$ & $12(46.2 \%)$ & $7(26.9 \%)$ & $1(3.9 \%)$ & $5(19.2 \%)$ & $26(100)$ \\
Higher & $0(0 \%)$ & $5(50 \%)$ & $1(10 \%)$ & $3(30 \%)$ & $1(10 \%)$ & $10(100)$ \\
\hline
\end{tabular}

Table 5. Practice of food hygiene by food handlers based on duration in food handling business

\begin{tabular}{lllllll}
\hline $\begin{array}{lllll}\text { Duration of stay } \\
\text { (Years) }\end{array}$ & \multicolumn{4}{c}{ Practice of food hygiene frequency (\%) } & Total (\%) \\
\cline { 2 - 6 } & Good & Fair & Poor & Very good & Very poor & \\
\hline $0-9$ & $0(0 \%)$ & $5(33.3 \%)$ & $2(13.3 \%)$ & $5(33.3 \%)$ & $3(20 \%)$ & $15(100)$ \\
$10-19$ & $0(0 \%)$ & $3(14.3 \%)$ & $5(23.8 \%)$ & $6(28.6 \%)$ & $7(33.3 \%)$ & $21(100)$ \\
$20-29$ & $3(25 \%)$ & $3(25 \%)$ & $2(16.7 \%)$ & $0(0 \%)$ & $4(33.3 \%)$ & $12(100)$ \\
$\geq 30$ & $0(0 \%)$ & $0(0 \%)$ & $1(50 \%)$ & $0(0 \%)$ & $1(50 \%)$ & $2(100)$ \\
\hline
\end{tabular}

Table 6. Microbial load of each culture media

\begin{tabular}{llll}
\hline & EMB agar (cfu) & PCA (cfu) & PDA (sfu) \\
\hline Total bacterial count & $57.0 \pm 0.0^{\mathrm{b}}$ & $38.0 \pm 0.1^{\mathrm{a}}$ & ND \\
Total fungal count & ND & ND & $19.0 \pm 0.1^{\mathrm{a}}$ \\
\hline \multicolumn{4}{c}{, Means across columns sharing different letter are significantly different $(P=.05)$} \\
\multicolumn{4}{c}{ Key: ND = Not determined }
\end{tabular}

Table 7. Types and prevalence of microbial isolates according to sample location

\begin{tabular}{llllllll}
\hline Bacteria & C1 & C2 & C3 & C4 & C5 & C6 & Total (\%) \\
\hline Escherichia coli & 2 & 3 & 2 & 5 & 4 & 2 & $18(18.9)$ \\
Enterobacter aerogenes & - & 2 & 2 & 2 & 3 & 5 & $14(14.7)$ \\
Salmonella sp. & 1 & 2 & 2 & 4 & 1 & 1 & $11(11.6)$ \\
Shigella sp. & - & 2 & 1 & 3 & - & - & $6(6.3)$ \\
Pseudomonas aeruginosa & - & 1 & - & 1 & - & 1 & $3(3.2)$ \\
Proteus vulgaris & 1 & 1 & 1 & 1 & 1 & - & $4(4.2)$ \\
Klebsiella pneumonia & - & - & 1 & 1 & 1 & - & $3(3.2)$ \\
Streptobacilli & - & 1 & - & - & - & 2 & $3(3.2)$ \\
Staphylococcus aureus & 2 & 3 & 4 & 2 & 2 & 4 & $17(17.9)$ \\
Bacillus cereus & 1 & 2 & 2 & 2 & 1 & 3 & $11(11.6)$ \\
Micrococcus luteus & - & 1 & 1 & - & 2 & 1 & $5(5.3)$ \\
Total & $\mathbf{7}$ & $\mathbf{1 8}$ & $\mathbf{1 5}$ & $\mathbf{2 1}$ & $\mathbf{1 5}$ & $\mathbf{1 9}$ & $\mathbf{9 5}(\mathbf{1 0 0})$ \\
Fungi & & & & & & & \\
Candida albicans & 1 & - & 2 & 1 & - & 1 & $5(26.3)$ \\
Aspergillus flavus & - & 1 & 1 & 1 & 1 & - & $4(21.1)$ \\
Aspergillus niger & 1 & - & - & - & 3 & 2 & $6(31.6)$ \\
Rhizopus sp. & - & - & 1 & - & - & - & $1(5.3)$ \\
Penicillium sp. & - & 1 & 1 & - & 1 & - & $3(15.7)$ \\
Total & $\mathbf{2}$ & $\mathbf{2}$ & $\mathbf{5}$ & $\mathbf{2}$ & $\mathbf{5}$ & $\mathbf{3}$ & $\mathbf{1 9}(\mathbf{1 0 0})$ \\
\hline & Key:C1-C6 Canteens 1 to 6 & & & &
\end{tabular}

\section{DISCUSSION}

This study showed that palms of food handlers harbour microorganisms. They can serve as means of transfer of these microorganisms to other humans and food. The involvement of more females in food handling business, as depicted in the socio-demographic characteristics, conforms largely with the report of Lawan et al. [13]. Musa and colleague [10] also reported that $98.4 \%$ of respondents were females. More (46\%) food handlers were in the age group 20-29 years compared to other groups in this study $[13,18]$. Similar study carried out in Ahmadu Bello University recorded $36 \%$ of food handlers between 20-29 years of age. $62 \%$ of the food 
handlers in this study were married person. This percentage is higher $(47.6 \%$ married $)$, and in contrast with more handlers (52.4\%) being single [18]. All the food handlers in this study were of the Yoruba tribe; possibly because the study was carried out in a Yoruba dominated area in a South-Western State in Nigeria. The area/region could significantly determine the tribal statistics/percentage. In line with this, Lawan et al. [13] recorded a highest percentage of Hausa vendors (34.47\%) in North-Western Nigeria. The largest proportions of the food handlers were those who had secondary education as their highest educational attainment (52\%). This group of individuals may have been involved in parttime food handling business pending admission into college or university for higher education. This however contradicts a research carried out in Kwara State where it was found that the largest proportion $(56.8 \%)$ of the food handlers had no formal education [10].

In our study, $24 \%, 26 \%$ and $22 \%$ of food handlers had very good knowledge, attitude and practice of food hygiene respectively. In contrast, the percentage of food handlers working in Mekelle university students' cafeteria who had good attitude towards food hygiene was relatively lower (19.1\%). $22 \%$ had poor attitude towards food hygiene. This could be attributed to lack of good knowledge of food hygiene or negligence [3]. In an assessment of personal hygiene of canteen workers of government medical college and hospital in Solapur, India by Anant and Anjali [19], the knowledge of food safety concepts did not generally correspond to practicing the procedure. This correlates with the findings of this study in which there was good knowledge $(42 \%)$ but the practice was only fair $(16 \%)$. This may be due to inconstant monitoring which encouraged the non-conformance to set standards [20]. For this reason, assessing the knowledge of food hygiene and its correct application amongst food handlers is very essential in preventing food-borne diseases. A combination of good knowledge and good attitude towards food hygiene cannot be overemphasized [1].

The proportion of handlers who had preemployment medical examination was also relatively low $(30 \%)$. This contradicts the finding by Musa and Akande [10] where they found that seventy six percent $(76 \%)$ of the food vendors had pre-employment medical examination. In this study, $20 \%$ of the primary school leavers had good hygiene practices whereas $46.2 \%$ of those who had higher education had just fair practice. Lawan et al. [13] reported $51 \%$ of respondents had at least secondary education with fair practice. Level of education had no major effect on good food hygiene practice. One reason for this may be that since cooking can be learnt informally, acquiring higher qualifications may not have appreciable effect on the outcome of cooking. There was no good correlation between attitude of handlers towards food hygiene and practice of food hygiene. This was also the submission of Lawan et al. [13]. Iwu et al. [21] also recorded level of knowledge $(81 \%)$ and positive attitude $(71 \%)$ about food hygiene, but with less than $40 \%$ of the respondents having good hygienic practices. A probable reason for this may be the lack of ideal facilities to translate good knowledge and attitude into good practice, or perhaps fair/poor practice became a habitual routine. In this study, twenty five percent (25\%) of those who had stayed for a longer period (between 20-29 years) in the business practiced good food hygiene. The reverse was the case in an assessment by Okojie et al. [8]. They reported poor practice of food hygiene among food handlers who had been in the business for a long period. Therefore, length of stay in business is not always directly proportional to business experience. Instead, regular food handlers' training may be a better way to achieve better hygiene practices [2].

The bacterial pathogens isolated in this study were similar to microorganisms reported by Ibrahim et al. [22] in a study carried out on bacteriological analysis and hygiene level of food. Some of these microorganisms such as Staphylococcus aureus, Escherichia coli, and Pseudomonas aeruginosa are normal skin flora and can be found on palms of food handlers; while others can be through contact with food and surfaces, especially surfaces the hand come in contact with most frequently [23]. E. coli is also listed as one of the major causes of food borne illnesses by WHO report [1]. A state of inadequate hygiene and poor sanitary practices could account for high counts in the samples [5]. Escherichia coli was the most predominant $(18.9 \%)$ bacterial isolate in this study. Lambrechts et al. [24] reported the presence of E. coli from the hands of food service employees. Onyango et al. [25] also recorded the presence of pathogenic $E$. coli among food handlers in Kenya's tourist destination hotels. In this study, it was also found that the fourth canteen had the highest number of isolates probably due to their poor hygiene standards. It was therefore 
surmised that the hygiene level of the food handlers was generally low due to the high occurrence of $E$. coli. This increases the possibility of food poisoning outbreaks. This calls for regular screening of food handlers, in addition to increasing public awareness as interventions to control the transmission of potential enteric pathogens. The results in this study also revealed the presence of fungi on the hands of food handlers. The moulds isolated include Aspergillus niger, Aspergillus flavus, Penicillium sp., Rhizopus sp., while Candida albicans was the only yeast isolated. $A$. niger fungus had the highest occurrence (31.6\%) of all fungal isolates. Although $A$. niger is less likely to cause human disease, but in rare cases, humans may contract serious lung disease (aspergillosis) [26]. Candida albicans yeast is a fungal pathogen that is responsible for candidiasis [27]. It was also discovered that the third and fifth canteens had the highest number of fungal isolates probably due to negligence and/or lack of knowledge of food hygiene.

\section{CONCLUSION}

Knowledge and attitude about food hygiene amongst the food handlers was good. However, the practice of food hygiene was mostly fair. Premedical examination history of the food handlers was not satisfactory, and knowledge and level of education did not always correlate with practice of food hygiene. The high occurrence of Escherichia coli indicated that the hygiene level of food handlers was generally low. Asymptomatic food handlers carrying enteric bacterial pathogens are potential sources of food-borne infections. Insistence on maintaining good hand hygiene is important. Enteropathogenic Escherichia coli and Staphylococcus aureus may cause harmful health effects to students considered as a highrisk group. Thus, health education is essential to create awareness about food-borne infections that are associated with unhygienic food handling practices. Local authorities and University health centre services need to increase awareness, while ensuring food handlers in cafeteria within their jurisdiction adhere to good food hygiene practices. Food safety communicators could also aid in getting the message across by fashioning out and utilizing novel systems aimed at increasing food safety risk-reduction practices. Continuous supervision and follow up also needs to be undertaken by relevant food hygiene/health inspection agencies.

\section{COMPETING INTERESTS}

Authors have declared that no competing interests exist.

\section{REFERENCES}

1. WHO. Food Safety Fact Sheet No. 399; 2015.

Available:http://www.who.int/mediacentre/f actsheets/fs399/en/

2. World Health Organization. The role of food safety in health and development. Report of the Joint $\mathrm{FAO} / \mathrm{WHO}$ expert committee in food safety. J. of Food and Drug Admin. 2003;56:534-535.

3. World Health Organization. Food-borne diseases; a focus for health education. 53rd World Health Assembly. Geneva. J. of Food Protect. 2000;43:344-347.

4. Alapati A. Food poisoning: Definition, symptoms, signs, causes, diagnosis, treatment, prevention \& lawyers. Health Chrome. The Bantam Medical Dictionary; 2011.

Available:http://www.emedicinehealth.com/ food-poisoning

(Retrieved June 11, 2016)

5. Aruwa CE, Akinyosoye FA. Microbiological assessment of ready-to-eat foods (RTEs) for the presence Bacillus species. J. Adv. Biol. and Biotech. 2015;3(4):145-152.

6. World Health Organization. WHO global strategy for food safety - food for better health. World Health Organization, Genera Switzerland. J. of Food Sci. and Tech. 2016;23:462-467.

7. Akonor PT, Akonor MA. Food safety knowledge: The case of domestic food handlers in Accra. Eur. J. Nut. Food Safety. 2013;3(3):99-111.

8. Okojie $\mathrm{OH}$, Wagbatsoma VA, Ighoroge AD. An assessment of food hygiene among food handlers in a Nigerian university campus. Niger. Postgrad. Med. J. 2005;12:93-96.

9. Chapman B, Eversley $\mathrm{T}$, Fillion $\mathrm{K}$, Maclaurin T, Powell D. Assessment of food safety practices of food service food handlers (Risk assessment data): Testing a communication intervention (Evaluation of tools). J. of Food Protect. 2010; 73(6):1101-1107.

10. Musa OI, Akande TM. Food hygiene practices of food vendors in secondary 
schools in Ilorin. Niger. Postgrad. Med. J. 2003;10:192-196.

11. Isara AR, Isah EC. Knowledge and practice of food hygiene and safety among food handlers in fast food restaurants in Benin City, Edo State. Niger Postgrad Med J. 2009:16:207-212.

12. Oranusi SU, Braide W. A study of microbial safety of ready-to-eat foods vended on highways: Onitsha-Owerri, South East Nigeria. Int'l Res. J. of Microbiol. 2012;3:066-071.

13. Lawan UM, lliyasu Z, Abubakar S, Gajida $\mathrm{AU}$, Abdussalam A. Personal and food hygiene practices of subsistence food vendors operating in Kano metropolis, northwestern Nigeria. Int'l J. Med. Sci. and Pub. Hlth. 2015;4:214-221.

14. Ifeadike CO, Ironkwe OC, Adogu PO, Nnebue CC. Assessment of the food hygiene practices of food handlers in the Federal Capital Territory of Nigeria. Trop. Jour. of Med. Res. 2014;17:10-15.

15. Hansen TB, Knøchel S. Image analysis method for evaluation of specific and nonspecific hand contamination. J. of Appl. Microbiol. 2003;94:483-494.

16. Dada EO, Aruwa CE. Asymptomatic bacteriuria prevalence among primary school children in the Federal University of Technology, Akure, Ondo State, Nigeria. Jour. of Appl. Life Sci. Int'l. 2016;4(4):1-8.

17. Cheesbrough $M$. District laboratory practice in tropical countries. Cambridge University Press, New York. 2nd (ed). 2005;38-39.

18. Mizanur R, Muhammad TA, Kamaluddin B, Zainab T. Food safety knowledge, attitude and hygiene practices among the street food vendors in Northern Kuching city, Sarawak. Borneo Sci. 2012;31:107-116.

19. Anant AT, Anjali PK. Assessment of personal hygiene of canteen workers of government medical college and hospital,
Solapur, India. Nat. Med. J. of India. $2011 ; 2(3): 448$.

20. FAO. Codex alimentarius, general requirements (Food hygiene). Rome: FAO. 1995;188-92.

21. Iwu AC, Uwakwe KA, Duru CB, Diwe KC, Chineke HN, Merenu IA, Oluoha UR, Madubueze UC, Ndukwu E, Ohale I. Knowledge, attitude and practices of food hygiene among food vendors in Owerri, Imo State, Nigeria. Occup. Dis. and Envir. Med. 2017;5:11-25.

22. Ibrahim TA, Odeyemi AT, Ola-lyabo $\mathrm{O}$. Isolation and identification of bacterial from hand towel used in drying hands in restaurants within Rufus Giwa Polytechnic, Owo, Ondo State, Nigeria. J. Env., Agric. and Food Chem. 2011;10:2234-2239.

23. Oranusi SU, Galadima M, Umoh VJ. Toxicity test and bacteriophage typing of Staphylococcus aureus isolates from food contact surfaces and foods prepared by families in Zaria, Nigeria. Afri. J. of Biotech. 2006;5:362-365.

24. Lambrechts AA, Human IS, Doughari JH, Lues JFR. Bacterial contamination of hands of food handlers as indicator of hand washing efficacy in some convenient food industries. Pak. J. Med. Sci. 2014:30:755-758.

25. Onyango AO, Kenya EU, Mbithi JJN, Ng'ayo MO. Pathogenic Escherichia coli and food handlers in luxury hotels in Nairobi, Kenya. Travel Med. and Infect. Dis. 2009;7:359-366.

DOI: 10.1016/j.tmaid.2009.07.005

26. Schuster E, Dunn-Coleman N, Frisvad JC, Van Dijck PW. On the safety of Aspergillus niger - A review. Appl. Microbiol and Biotech. 2002;59:426-35.

DOI: 10.1007/s00253-002-1032-6

27. Kabir MA, Hussain MA, Ahmed Z. Candida albicans: A model organism for studying fungal pathogens. 8th (ed). 2012;37.

(0) 2017 Aruwa et al.; This is an Open Access article distributed under the terms of the Creative Commons Attribution License (http://creativecommons.org/licenses/by/4.0), which permits unrestricted use, distribution, and reproduction in any medium, provided the original work is properly cited.

Peer-review history:

The peer review history for this paper can be accessed here: http://sciencedomain.org/review-history/19363 